\title{
IdeAs
}

Idées d'Amériques

$6 \mid 2015$

Migrer dans les Amériques

\section{Cinquante ans après la loi sur l'Immigration et la Nationalité (Immigration and Nationality Act)....}

\section{Isabelle Vagnoux}

\section{(2) OpenEdition}

1 Journals

\section{Édition électronique}

URL : https://journals.openedition.org/ideas/1288

DOI : $10.4000 /$ ideas. 1288

ISSN : 1950-5701

Éditeur

Institut des Amériques

\section{Référence électronique}

Isabelle Vagnoux, "Cinquante ans après la loi sur l'Immigration et la Nationalité (Immigration and Nationality Act).... », IdeAs [En ligne], 6 | 2015, mis en ligne le 18 décembre 2015, consulté le 19 octobre 2022. URL : http://journals.openedition.org/ideas/1288; DOI : https://doi.org/10.4000/ideas.1288

Ce document a été généré automatiquement le 19 octobre 2022

\section{(c) (i) (9)}

Creative Commons - Attribution - Pas d'Utilisation Commerciale - Pas de Modification 4.0 International - CC BY-NC-ND 4.0

https://creativecommons.org/licenses/by-nc-nd/4.0/ 


\title{
Cinquante ans après la loi sur l'Immigration et la Nationalité (Immigration and Nationality Act)....
}

\author{
Isabelle Vagnoux
}

1 «Nous sommes une nation d'immigrants " lançait John F. Kennedy en 1958, formule qu'il reprit dans le titre d'un ouvrage publié en 1963. L'objectif était clair : il s'agissait de convaincre le Congrès de revoir en profondeur un dispositif législatif devenu obsolète afin de le mettre au diapason de la mission des États-Unis en tant que leader $\mathrm{du}$ «monde libre ». Ce fut au président Lyndon B. Johnson qu'il revint de signer la loi sur l'Immigration et la Nationalité (connue également sous le nom de loi Hart-Celler), il y a tout juste cinquante ans, le 3 octobre 1965, à une époque où moins d'un pour cent des Américains sondés considéraient l'immigration comme le principal problème du pays (Kohut A., 2015). Depuis, bien des amendements ponctuels ont été ajoutés, le nombre de visas est régulièrement revu, et plusieurs mesures concernant surtout les immigrés en situation irrégulière ont été adoptées, mais plus aucun président n'est parvenu à obtenir du Congrès une nouvelle grande réforme générale, comme le montre Bénédicte Deschamps dans le panorama qu'elle présente dans ce dossier.

2 James Cohen s'attache quant à lui à souligner les effets pervers de cette loi sur le principal groupe de migrants à destination des États-Unis, les Mexicains. Le recensement de 1960 n'en comptait que 576 000, soit 5,9\% de la population immigrée. Ils sont aujourd'hui quelque 11,5 millions, soit $28 \%$, après avoir atteint un nombre record en 2007. Si l'on y ajoute les migrants des autres pays d'Amérique latine et des Caraïbes, l'immigration des Amériques (Canada exclu) représente 52\% de la population née à l'étranger, dont une proportion significative de personnes en situation irrégulière (Brown A. et Stepler R., 2015). En d'autres termes, toute mesure, tout débat portant sur l'immigration concernent au premier chef la population hispanique. L'immigration constitue aujourd'hui l'un des principaux sujets de débat politique, comme en attestent les premiers échanges de la campagne présidentielle américaine. Le curseur s'est 
cependant déplacé: la question ne porte plus tant sur l'ouverture du pays à l'immigration légale que sur l'attitude à adopter envers ceux en situation irrégulière.

3 Faute de réforme au niveau national et afin de gérer la présence de quelque 41 millions d'immigrés, dont plus de 11 millions en situation irrégulière, les États et les villes se sont emparés de la question, générant un flot de législations locales (288 lois ou résolutions passées par les États en 2014, National Conference of State Legislatures, 2015) qui amènent, pour les immigrés, notamment les sans papiers, des conditions de vie sensiblement différentes d'un lieu à un autre. Alors que certains États (Arizona, Georgie, Alabama ou Caroline du Sud) se sont rendus célèbres en adoptant des lois restrictives et punitives en 2010 et 2011 - lois largement démembrées depuis par les cours de justice -, d'autres États ou certaines villes entreprennent d'accueillir les immigrés le mieux possible et de faciliter leur intégration. C'est ce dernier aspect que développe Els de Graauw dans une étude consacrée aux services chargés localement de l'accueil des immigrés.

4 Cinquante ans après la loi sur l'Immigration et la Nationalité de 1965, les États-Unis, «nation d'immigrants» se trouvent plus que jamais enfermés dans leurs contradictions, tiraillés entre accueil et rejet.

\section{BIBLIOGRAPHIE}

Brown, Anna et Renée Stepler, « Statistical Portrait of the Foreign-Born Population in the United States, 1960-2013 », Pew Hispanic Center, 28 septembre 2015, http://www.pewhispanic.org/ 2015/09/28/statistical-portrait-of-the-foreign-born-population-in-the-united-states-1960-2013/, consulté le 13 décembre 2015.

Kohut, Andrew, « 50 years later, Americans give thumbs-up to immigration law that changed the nation », Pew Research Center, 4 février 2015, http://www.pewresearch.org/fact-tank/ 2015/02/04/50-years-later-americans-give-thumbs-up-to-immigration-law-that-changed-thenation/, consulté le 13 décembre 2015.

National Conference of State Legislatures, 2014 Immigration Report, 7 janvier 2015, http:// www.ncsl.org/research/immigration/2014-immigration-report.aspx, consulté le 8 septembre 2015.

\section{AUTEUR}

\section{ISABELLE VAGNOUX}

Professeur des Universités à Aix-Marseille Université (LERMA, EA 853), Isabelle Vagnoux est spécialiste de politique étrangère américaine, notamment des relations entre les Etats-Unis et l'Amérique latine, ainsi que de la minorité hispanique aux Etats-Unis. Elle est rédactrice-en-chef de la revue électronique IdeAs. 